\title{
SOME ASPECTS OF THE NESTING OF DOUBLE-CRESTED CORMORANTS AT CYPRESS LAKE, SASKATCHEWAN, IN 1969; A PLEA FOR PROTECTION
}

by Kees Vermeer, Canadian Wildlife Service, Edmonton

During April and May, 1969, I visited 210-acre Heglund Island in Cypress Lake, $49^{\circ} 28^{\prime} \mathrm{N}$; $109^{\circ} 28^{\prime} \mathrm{W}$, in extreme southwestern Saskatchewan (Fig. 1). The island is hilly with its highest point about 150 feet above the lake and consists chiefly of open meadow with greasewood bushes at the southwest tip and gooseberries and sagebrush at other locations. The nearest distance from the island to the mainland is about 2400 feet.

White-tailed jack rabbits were observed at various times and a dead striped skunk was also found. These animals may have arrived on the island from the mainland by crossing the ice in the winter. Approximately 40 head of cattle were introduced on the island in the second half of May.

Ninety nests of Canada Geese were found widely distributed over the island. Several pairs even nested on the hilltops. Thirty-seven nests of Mallards and two nests of American Widgeons were found. The nests of Mallards, like those of the geese, were widely distributed over the island and several nests were on the hilly ridges. Three nests of that species were observed in concealed earth fissures caused by slumping near the shore.

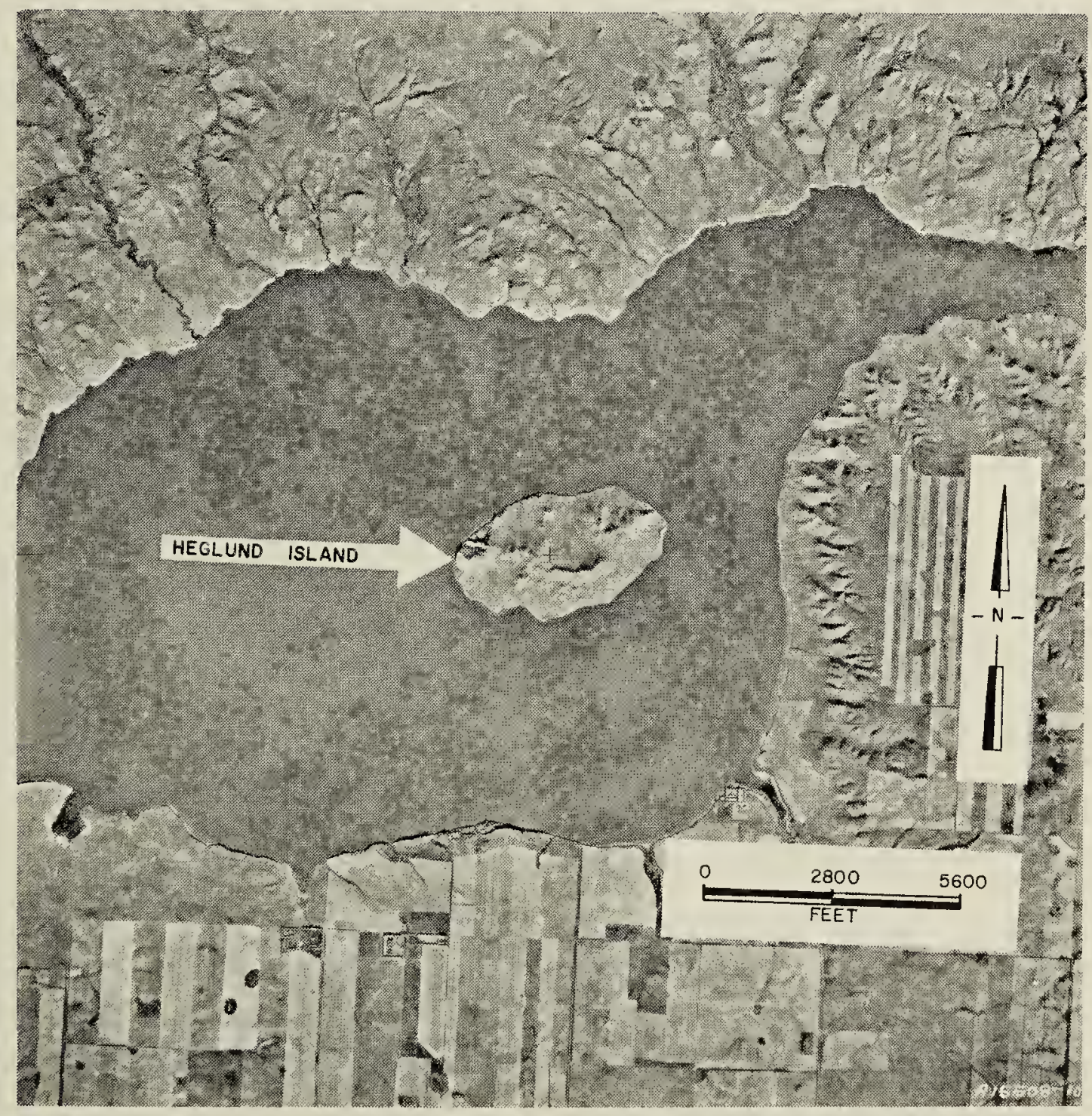

Canadian Government Photo

Fig. 1. Air photo of Heglund Island in Cypress Lake 
Passerines such as Bank Swallows, Brewer's Blackbirds, Red - winged Blackbirds and Vesper Sparrows nested on the island.

Colonies of California Gulls, Ringbilled Gulls, White Pelicans and Double-crested Cormorants were also present. Although 12 clutches of White Pelicans were initiated, they were deserted later on.

\section{Nesting Pattern of Cormorants}

The cormorant colony, with its 434 nests, is the largest of 10 colonies of this species in Saskatchewan (Vermeer, in press). The cormorant nests were separated from the insular meadow by greasewood bushes. During the first visit to Cypress Lake on April 17, the island could not be reached as the lake was covered with ice. From the mainland, between 100 to 200 cormorants could be observed occupying the nesting area on that date. The cormorants started egglaying soon after as 35 clutches with one and three clutches with two eggs were counted on April 24. On April 30 there were 68 clutches with one egg, 36 with two, 16 with three, 15 with four and 1 with five eggs. The colony

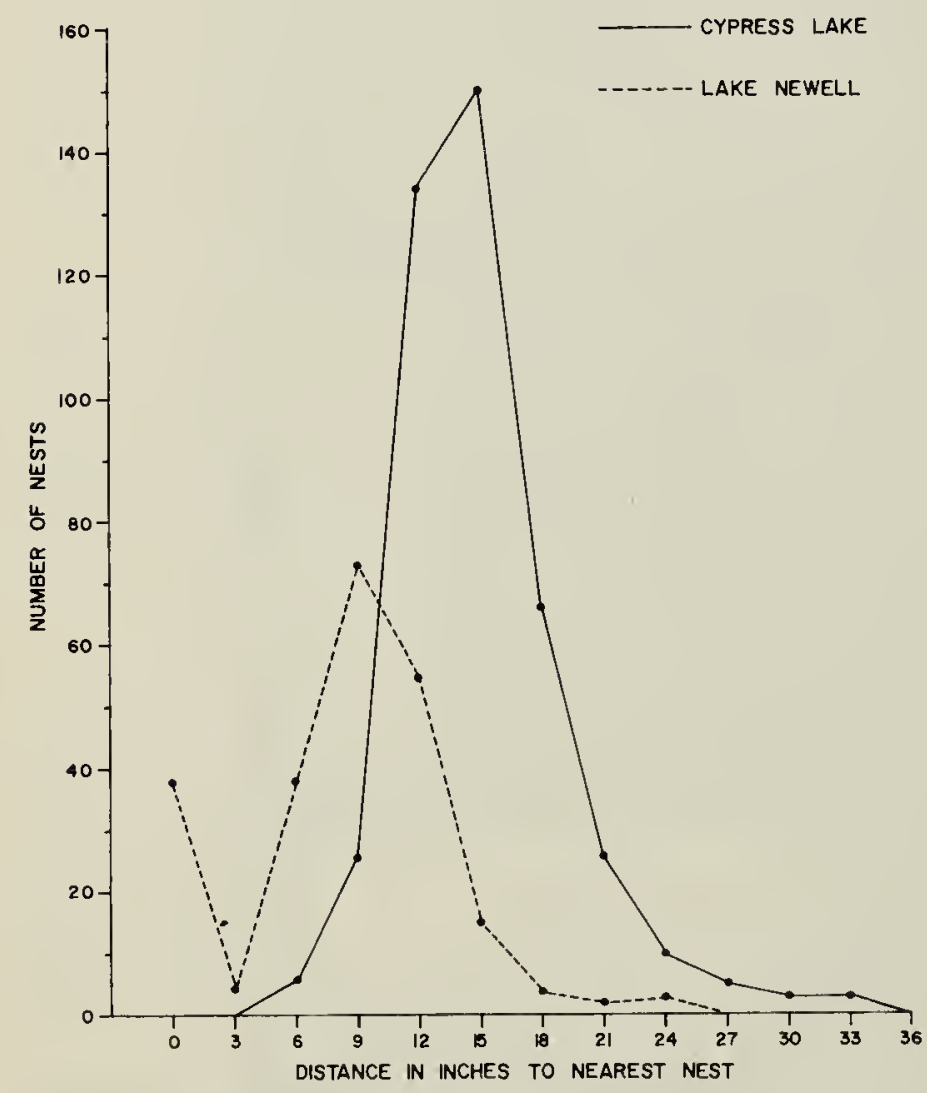

Fig. 2. Distribution of distances between Double - crested Cormorant nests at Cypress Lake and Lake Newell. was made up of four nesting nuclei. These nuclei consisted of $42,144,166$ and 82 nests and were separated from one another by distances of 10,24 , and 8 feet respectively. On April 24, the distances between the rims of each nest and its nearest neighbour were measured to the nearest three inches for the purpose of learning more about the nest distribution of the cormorants. The distances between nests were also measured in a cormorant colony with 232 nests on a three-acre island in Lake Newell, $50^{\circ}$ $24^{\prime} \mathrm{N} ; 111^{\circ} 58^{\prime} \mathrm{W}$, Alberta in 1969 for comparison with those at Cypress Lake (Fig. 2). The mean nesting distances for cormorants at Cypress Lake and Lake Newell were 14.98 and 8.48 inches respectively. The difference between those mean distances was statistically significant $(\mathrm{P}<0.01)$. The nests at Lake Newell were approximately three or four times taller than those at Cypress Lake, possibly reflecting a longer established colony. It can be seen that 38 nests at Lake Newell, which were among the tallest structures, were attached to one another (Fig. 2). Although attached, they may have been initially separated as observed for recently built, low nests in that colony. An increment in nesting height leads to the accumulation of nesting material which may give rise to several massive supporting structures with many nest bowls each (Fig. $3)$. Hence, the smaller nesting distance of cormorants at Lake Newell may be related to taller nests which in turn may be the result of colony age and/or climatic conditions favouring the preservation of nesting platforms.

The Clark-Evans (1954) method was used to test whether the observed distribution of cormorant nests at Cypress Lake and Lake Newell departed from a random distribution. The distribution of nests at both colonies showed a highly significant deviation from randomness in the direction of aggregated spacing ( $P$ $<0.01)$. In five cormorant colonies ranging from two to five nests in the Canadian prairie provinces, I observed 


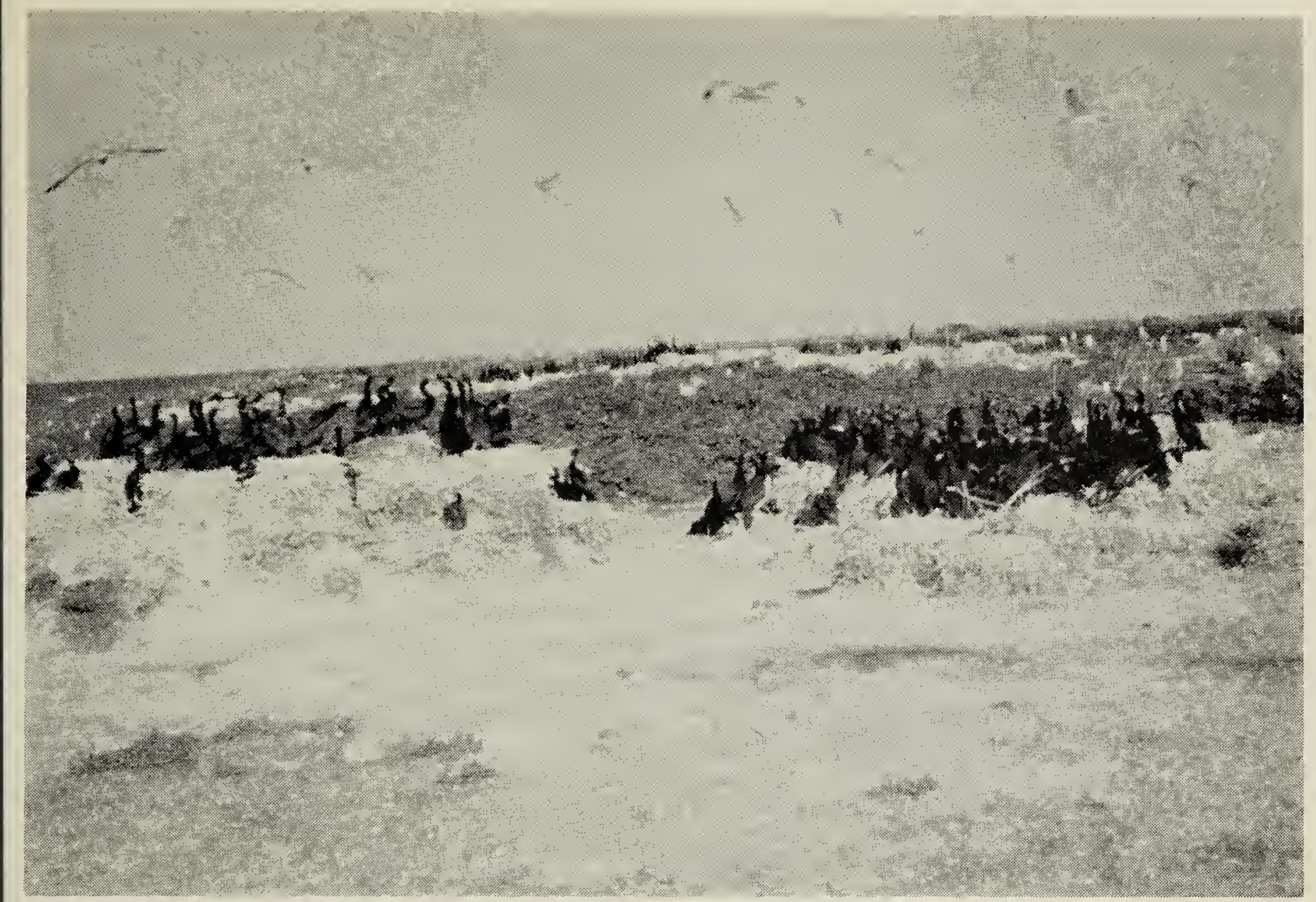

Fig. 3. Nests of Double-crested Cormorants at Lake Newell, Alberta

that cormorants also nested in an aggregated pattern like those at $\mathrm{Cy}$ presis Lake and Lake Newell. The reason why cormorants nest in an aggregated pattern is unknown. Perhaps it is an anti-predator device directed against avian predators such as gulls and crows. California Gulls were observed to prey on the cormorant eggs between the time period when I left the colonies and the return of the cormorants to their nesting sites. Drent and Guiguet (1963) report crows to be extensive predators on eggs and young of cormorants in British Columbia in similar situations. Crows and gulls may have less opportunity to take eggs and recently hatched young than when the nests of cormorants would be more dispersed.

\section{Plea for Protection}

The number of breeding cormorants at Cypress Lake made up more than one-third of the total breeding population of cormorants in Saskatchewan (Vermeer, in press). This, plus the fact that the 90 breeding pairs of
Canada Geese may constitute one of the largest concentrations of insular nesting geese in Saskatchewan, may be justification for urging special protection for the nesting island. As the island is 210 acres in size it can provide the public with unique opportunities to observe those species in their natural environment with minimal interference. If cattle could be barred and indiscriminate motor-boat landings prohibited, the pelicans might start a more successful and permanent colony than that observed in 1969. Since the island is owned by the province of Saskatchewan, now leased to a rancher, it should be possible to acquire the area without much financial cost.

\section{LITERATURE CITED}

Clark, P. J., and F. C. Evans. 1954. Distance to nearest neighbour as a measure of spatial relationships in populations. Ecology $35: 445-453$.

Drent, R. H., and C. J. Guiguet. 1961. A catalogue of British Columbia seabird colonies. Occ. Pap. No. 12. Provincial Museum, Victoria, B.C.

Vermeer, K. Colonies of Double-crested Cormorants and White Pelicans in Saskatchewan. Canadian Field Naturalist (in press). 